\title{
Electric scooter vs. motorcycle injuries - little toys with an underestimated impact
}

\author{
Silvia Nica***, Irina-Anca Eremia***, Maria-Adriana Albu*, Adrian Cursaru*****, Siegfried-Daniel Albu* \\ *Emergency Department, University Emergency Hospital Bucharest, Romania \\ **"Carol Davila" University of Medicine and Pharmacy, Bucharest, Romania \\ ***Othopaedic Department, University Emergency Hospital Bucharest, Romania
}

Correspondence to: Silvia Nica, MD, "Carol Davila" University of Medicine and Pharmacy, Bucharest, 8 Eroii Sanitari Blvd., District 5, Code 050474, Bucharest, Romania Mobile phone: +40721262 030, E-mail: silvia.nica@umfcd.ro

\begin{abstract}
Introduction: The study weighs the impact of accidents involving electric scooters and motorcycles, its main purpose being that of showing the injuries produced by the use of electric scooters.

Materials and method: The retrospective study was conducted in the Emergency Unit of the University Emergency Hospital Bucharest, Romania, between 01.06.2020 and 30.09.2020, by analyzing the data from the presentation sheets and the hospital database. It followed and compared a total of 55 cases, out of which 29 patients were involved in motorcycle accidents, and 26 patients were involved in electric scooter accidents, by number, age, sex, imaging investigations, severity of injuries, hospitalization days, and the treatment of discharged patients.

General data about the number of analyzed presentations was extracted and compared to similar data from the same period of the year 2019.

Results: The study showed an increase in presentations due to electric scooter accidents. Also, most of the injuries in both types of accidents are musculoskeletal ( $96.5 \%$ in motorcycle accidents and $84.61 \%$ in electric scooter accidents), and the percentage of discharged patients who needed immobilization by various orthopedic devices was higher in electric scooter accidents (34.8\%) than in motorcycle accidents (26\%).

Discussions: The study was conducted in the middle of the COVID-19 pandemic, in an atypical situation, due to regulations imposed by the authorities.

Conclusion: There was an increase in the use of electric scooters in the summer of 2020, which resulted in an increased number of mainly orthopedic injuries, and implicitly of immobilization for discharged patients, underestimated by the population, as protective equipment is not mandatory for people aged over 16 years.

Keywords: electric scooter, motorcycle, injury, accident, trauma
\end{abstract}

\section{Introduction}

Busy traffic in big cities is a global problem, and, previous to finding real infrastructure solutions, the population is adapting, so transport by alternative means (personal or rented) is rising.

People are looking for fast, cost- and timeefficient means of transport, which should be as small as possible, easy to park in cramped 
spaces as close as possible to their places of interest (personal or work-related).

To satisfy these needs, the number of people using motorcycles, electric or manual scooters, electric or manual bicycles, and mopeds, has increased.

Particularly, the use of transport by electric scooter has increased in the summer of 2020, due to the proliferation of e-scooter rental companies, and, on the other hand, to the COVID-19 pandemic, which forced people to adapt to new measures of personal protection and social distancing.

The e-scooter rental companies are newcomers in Europe and the rest of the world, e.g.: July 2020 - United Kingdom [1], January 2019 - Denmark [2], June 2019 Germany [3], July 2019 - Singapore [4], end of 2017 - USA [3].

Consequently, there were very few studies analyzing electric scooter - related injuries; the first European study being done in Copenhagen [2] and published by the end of 2019. The most recent studies were published in the United States, at the end of May [5], July [6], and August [7] 2020.

Electric scooter rental companies began operating in Bucharest on April $19^{\text {th }}, 2019$, using easy to download smart phone apps, which show the route on a local map. The rented scooter is left by the user when reaching the destination, to be picked up by another user.

Travelling by electric scooter on public roads is regulated in Romania by an emergency government order, adopted on February $4^{\text {th }}, 2020$, to modify the older Governmental Order no. 195/2002 [8].

Electric scooters [9] can be used by people over 14 years of age, with mandatory protection helmet under 16 years old, with a maximum speed of $25 \mathrm{~km} / \mathrm{h}$. Under the new law, they cannot be used on the sidewalk, except for those that have bicycle tracks.

In conclusion, renting an electric scooter is a fast, easy, and cheap alternative transport solution.

The retrospective study, conducted over a period of four months on patients presented in the Emergency Department of the University Emergency Hospital Bucharest, showed the general characteristics of electric scooter related injuries, by number, age, sex, and type, and compared them with motorcycle accident-related injuries.

Apparently, these two types of vehicles are at opposite poles as far as speed is concerned, electric scooters being limited at $24 \mathrm{~km} / \mathrm{h}$ by all rental companies, while motorcycles are used at much higher speeds on all public roads [10].

The answer to a simple question - can the use of electric scooters and/ or motorcycles be related to serious orthopedic injuries - will at first make us think of motorcycles.

The study showed the increasing number of electric scooter related accidents and the importance and severity of orthopedic injuries involved, in comparison with those produced by motorcycle accidents, and their underestimated severity by the general population.

\section{Materials and methods}

The retrospective observational study was conducted in the Emergency Department of the University Emergency Hospital Bucharest, using data collected between 01.06.2020 and 30.09.2020.

We used statistical data from the University Emergency Hospital Bucharest database and we analyzed the presentation sheets of patients seen in the Emergency Department of the University Emergency Hospital Bucharest during this period with road accidents, selecting those involving electric scooters and motorcycles.

We followed and compared the patients by number, age, sex, required imagistic investigations for diagnosis, severity of the injuries and need for surgical intervention, admission and number of hospitalization days, the presence of injuries not needing admission and their treatment.

Statistic general data about the number of cases analyzed in the study was compared with the data from the same four months period of the year 2019, including road 
accidents involving electric scooters and motorcycles.

\section{Results}

In the four months period of the study, 55 patients presented in the Emergency Department of the University Emergency Hospital Bucharest - by their own means or brought by ambulance - after accidents involving electric scooters or motorcycles, out of a total of 437 patients from road accidents.

Out of these, 29 patients were involved in motorcycle accidents (drivers or passengers), and 26 patients had electric scooter accidents (drivers).

As shown in Fig. 1, young people and young adults have the highest percentage in both categories.

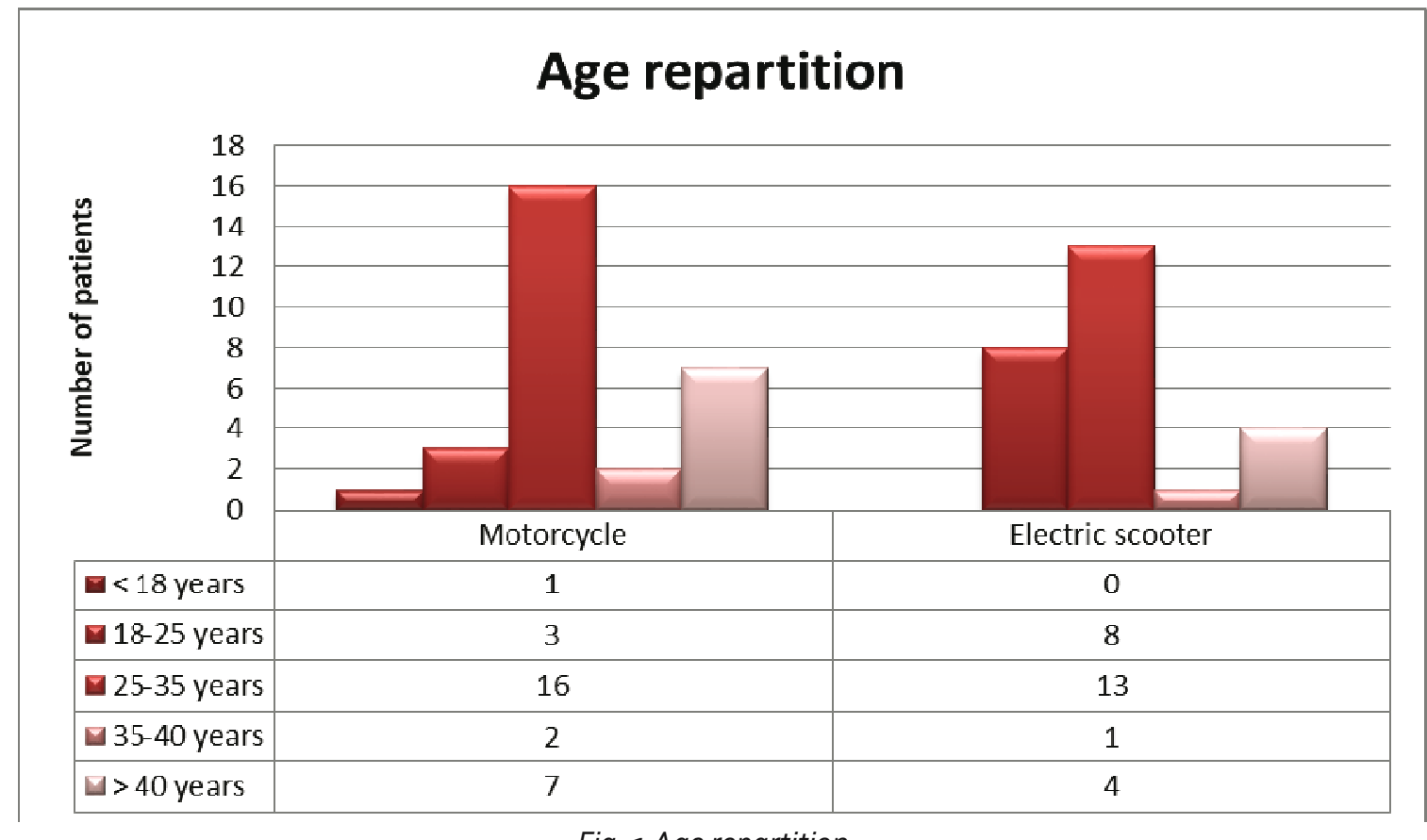

Fig. 1 Age repartition

In electric scooter accidents, 22 patients $(84.61 \%)$ were under 40 years of age, and also 22 patients under 40 years old $(75.86 \%)$ were involved in motorcycle accidents. Patients over 40 years of age were far fewer -4 patients (15.38\%) in electric scooter accidents, and 7 patients $(24.13 \%)$ in motorcycle accidents. Only one patient (motorcycle passenger) was younger than 18 years.

In both categories of accidents, the majority involved male patients - 93.10\% in motorcycle accidents, and $73.07 \%$ in electric scooter accidents - but there was an increase in electric scooter use by females $(26.92 \%$, compared to $6.89 \%$ in motorcycle accidents), as shown in Fig. 2.
To diagnose the patients, blood tests were obtained, and imaging investigations were performed.

A single patient (electric scooter driver) was driving under the influence of alcohol.

Motorcycle accidents required the performing of 23 abdominal ultrasound exams (one positive - hemoperitoneum by mesenteric rupture - and 22 negative), 32 thoracic or limb radiographs (14 showing injuries and 18 without injuries), and 12 CT scans ( 2 with craniocerebral injuries and 10 without lesions). For a single patient, with polytrauma and cardiac arrest, the only investigations were blood tests and an abdominal ultrasound (normal). 


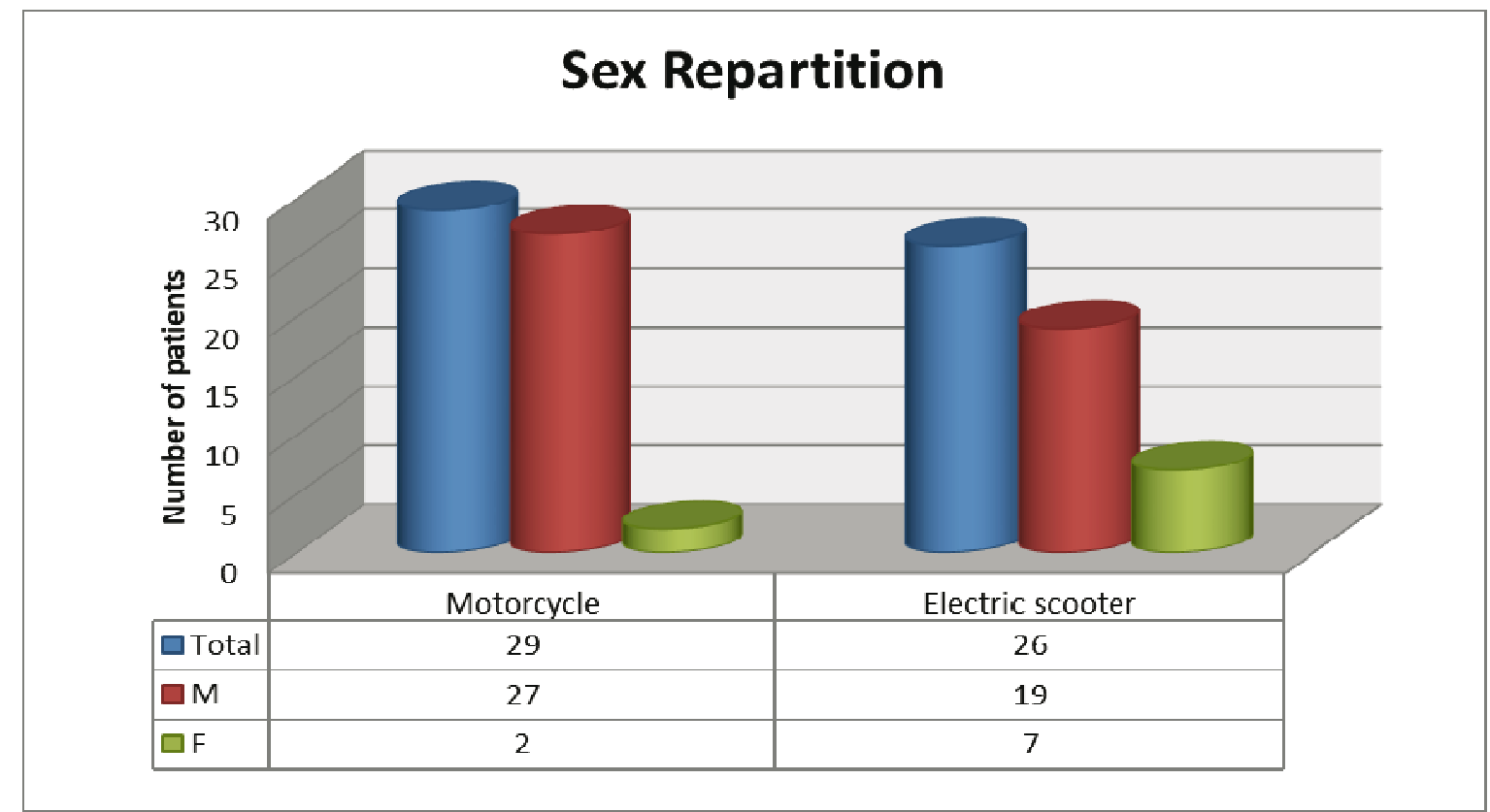

Fig. 2 Sex repartition

Electric scooter accidents required 17 abdominal ultrasound exams (all normal), 29 thoracic or limb radiographs (14 showing injuries, 15 without lesions), and 2 CT scans (one showing subarachnoid hemorrhage and one normal).

Out of the 29 motorcycle accident patients, 5 required hospital admission, one patient installed cardiac arrest and died in the emergency department, and 23 patients were discharged.

Out of the 26 electric scooter patients, 3 required admission and 23 were discharged.

As shown in Fig. 3, the percentage difference between the two types of accidents, in case of admitted patients, as well as discharged patients, was small.

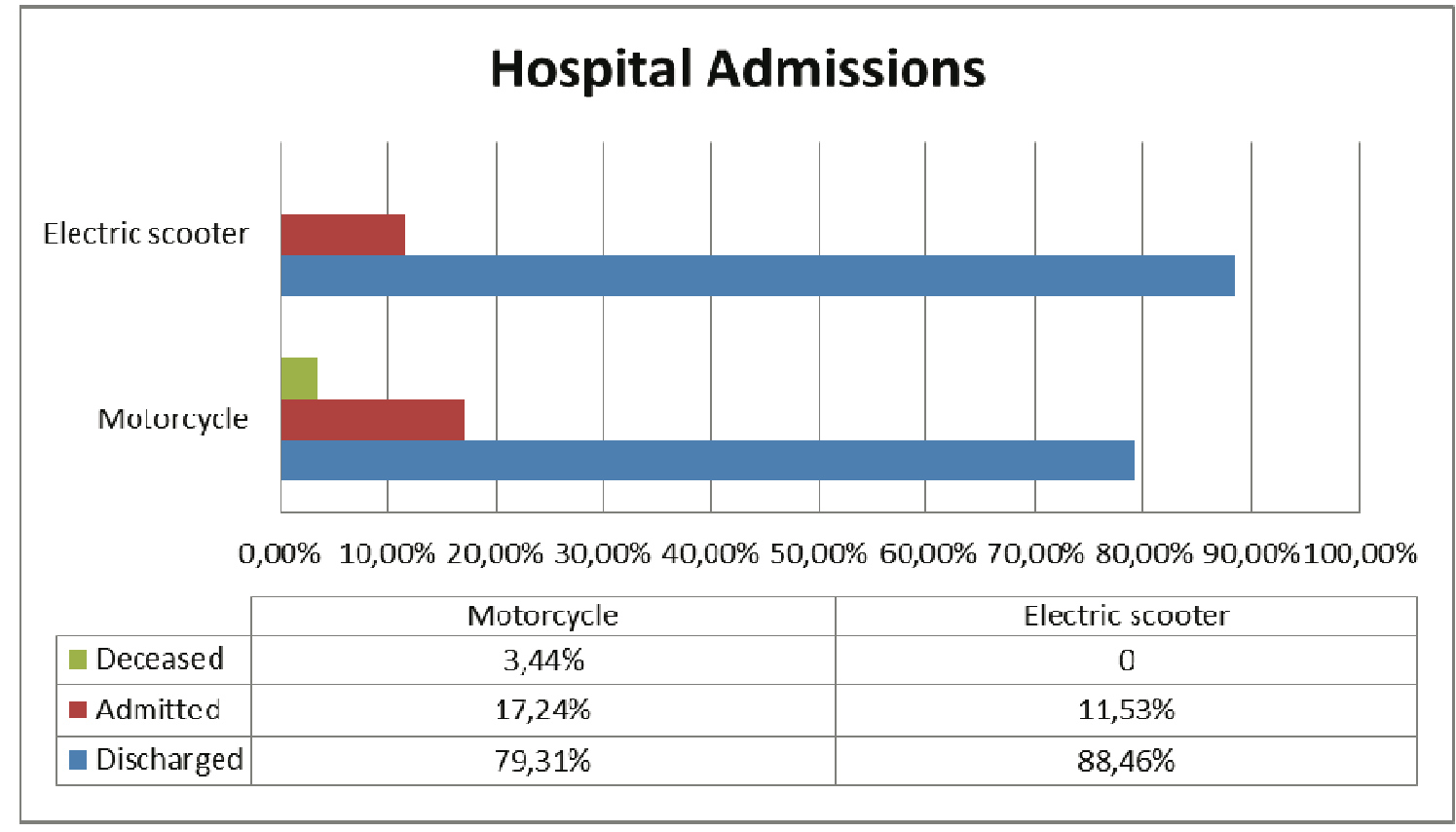

Fig. 3 Hospital admissions 
The investigations showed that the majority of injuries were orthopedic, alone or associated with other segments/ organs injuries, in both types of accidents: $96.50 \%$ orthopedic injuries in motorcycle accidents and $84.61 \%$ orthopedic injuries in electric scooter accidents (Fig. 4).

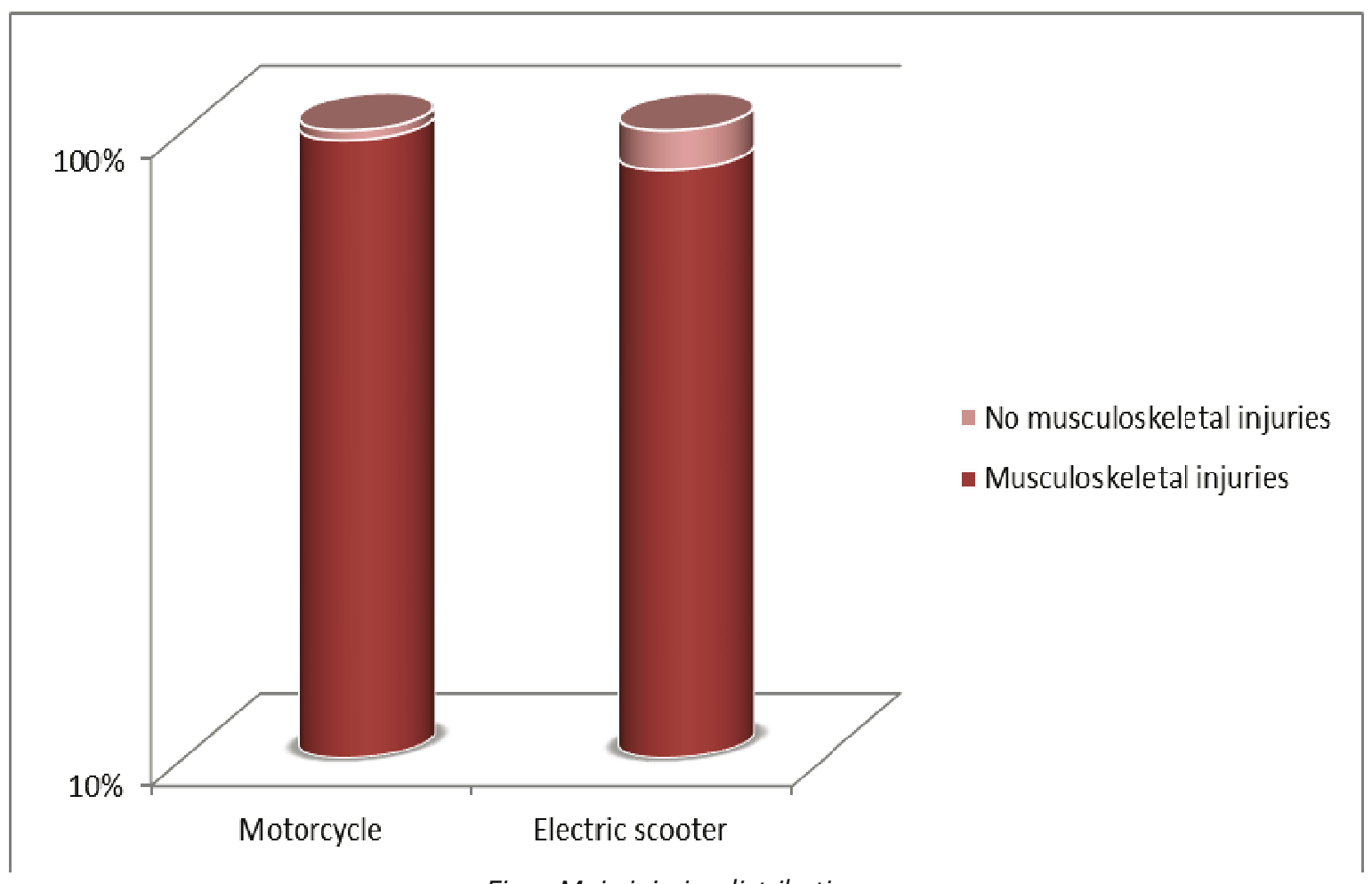

Fig. 4 Main injuries distribution

Furthermore, 18 electric scooter patients (69.23\%) sustained only musculoskeletal injuries, compared to 12 patients (41.37\%) on motorcycles.

Second place went to craniocerebral injuries associated with musculoskeletal injuries: 7 patients $(24.13 \%)$ on motorcycles, and 4 patients (15.38\%) on electric scooters.
Only one motorcycle patient (3.44\%) and one electric scooter patient (3.84\%) - driving under the influence of alcohol - had only craniocerebral injuries.

Table 1 details the distribution and localization of injuries.

Table 1. Distribution and localization of injuries

\begin{tabular}{lll}
\hline INJURY TYPE & Motorcycle & Electric scooter \\
Musculoskeletal & $12(41.37 \%)$ & $18(69.23 \%)$ \\
Severe polytrauma & $1(3.44 \%)$ & - \\
\hline Musculoskeletal + craniocerebral & $7(24.13 \%)$ & $4(15.38 \%)$ \\
Musculoskeletal + face lacerations & $3(10.34 \%)$ & - \\
\hline Musculoskeletal + thoracic & $2(6.89 \%)$ & - \\
Musculoskeletal + abdominal & $2(6.89 \%)$ & - \\
\hline Musculoskeletal + urogenital & $1(3.44 \%)$ & - \\
\hline Craniocerebral + face lacerations & - & $2(7.69 \%)$ \\
Craniocerebral & $1(3.44 \%)$ & $1(3.84 \%)$ \\
Face lacerations & - & $1(3.84 \%)$ \\
\hline
\end{tabular}


Table 2 shows all injuries, in both types of accidents.

Table 2. Injury types

\begin{tabular}{|c|c|c|}
\hline Trauma type & Motorcycle & Electric scooter \\
\hline Facial & $\begin{array}{l}\text { Facial bruising and lacerations } \\
\text { requiring suture - } 3\end{array}$ & $\begin{array}{l}\text { Facial bruising and lacerations } \\
\text { requiring suture }-10 \\
\text { Nasal fracture }-1\end{array}$ \\
\hline Vertebral & T11 compression fracture -1 & \\
\hline Craniocerebral & $\begin{array}{l}\text { With loss of consciousness - } 1 \\
\text { Without loss of consciousness - } 8 \\
\text { Severe - } 1\end{array}$ & $\begin{array}{l}\text { With loss of consciousness }-1 \\
\text { Without loss of consciousness -1 } \\
\text { Severe - } 1\end{array}$ \\
\hline Thoracic & $\begin{array}{l}\text { Contusions }-4 \\
\text { Rib fractures - } 3\end{array}$ & Contusions - 2 \\
\hline Abdominal & $\begin{array}{l}\text { Contusions }-2 \\
\text { Hemoperitoneum by mesentery } \\
\text { rupture-1 }\end{array}$ & Contusions - 1 \\
\hline Urologic & Urethrorrhagia - 1 & \\
\hline Musculoskeletal - upper limb & $\begin{array}{l}\text { Upper limb contusions }-18 \\
\text { Acromioclavicular disjunction }-2 \\
\text { Scapular fracture }-1 \\
\text { Radial head fracture }-1 \\
\text { Metacarpal fracture }-1 \\
\text { Wounds requiring suture }-2\end{array}$ & $\begin{array}{l}\text { Upper limb contusions }-17 \\
\text { Acromioclavicular disjunction }-1 \\
\text { Humeral fracture }-2 \\
\text { Radial fracture }-1 \\
\text { Phalanx fractures }-2 \\
\text { Wounds requiring suture }-4\end{array}$ \\
\hline Musculoskeletal - lower limb & $\begin{array}{l}\text { Lower limb contusions - } 18 \\
\text { Fibular head avulsion }-1 \\
\text { Severe ankle sprain - } 1 \\
\text { Pelvic fractures }-2 \\
\text { Tibial fractures }-2 \\
\text { Fibular malleolus fracture }-1 \\
\text { Bimalleolar fracture }-1 \\
\text { Foreign body, right knee }-1 \\
\text { Wounds requiring suture }-2\end{array}$ & $\begin{array}{l}\text { Lower limb contusions }-16 \\
\text { Knee sprain }-1 \\
\text { Severe ankle sprain }-1 \\
\text { Tibial fracture }-1 \\
\text { Fibular malleolus fracture }-1 \\
\text { Ankle fractures }-2\end{array}$ \\
\hline
\end{tabular}

The five admitted motorcycle patients all had musculoskeletal injuries, as it followed: 2 only had limb fractures and 3 had orthopedic injuries associated with other types of lesions (see Table 3).

Table 3. Patients admitted and hospitalization days

\begin{tabular}{lll}
\hline Accident type & Injury type & Hospitalization days \\
Motorcycle & Musculoskeletal & 5 \\
& Musculoskeletal & 3 \\
& Abdominal + musculoskeletal +16 \\
& craniocerebral +facial & \\
& Musculoskeletal + thoracic & +5 \\
& vertebral & \\
& Craniocerebral + musculoskeletal + & 4 \\
& abdominal & \\
Electric scooter & Musculoskeletal & 8 \\
& Musculoskeletal & 4 \\
\hline
\end{tabular}

Out of the 3 patients admitted with electric scooter accidents, 2 had only orthopedic injuries, and 1 had only craniocerebral injuries (see Table 3). 
Immobilization by various orthopedic devices (splints, casts, bandages), for various periods of time (7-21 days), with partial functional impairment for a limited time and orthopedic monitoring, was necessary for 8 out of the 23 discharged patients with electric scooter accidents and 6 out of the 23 discharged patients with motorcycle accidents (Fig. 5).

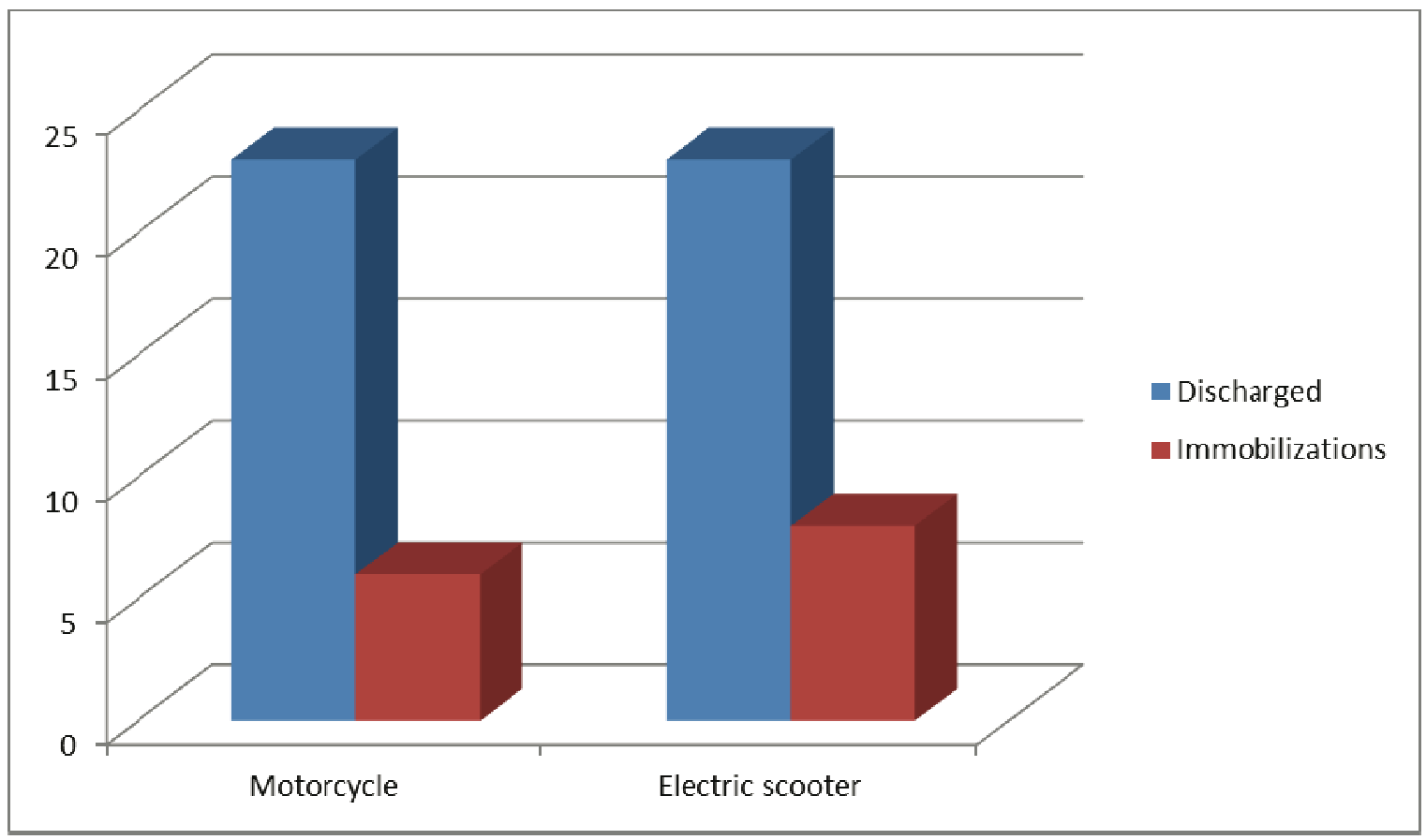

Fig. 5 Discharged patients and immobilizations

\section{Discussions}

The study was retrospective and began two weeks after Romania's exit from the lockdown caused by the COVID-19 pandemic.

In these conditions of increased risk for SARS-CoV-2 infection, Romania maintained a state of emergency after the lockdown, that included recommendations for isolation at home and limiting travel and public and private events. The study took place in this state of emergency period.

The COVID-19 pandemic caused major changes all over the world, affecting air and land transportation, and promoting social distancing. This led to the proliferation of alternative transport means, and the adopting of laws to regulate the activity of electric scooter rental companies, in the European countries where those did not exist before (e.g.: July 2020 in the UK).

As far as we know, this is the first post lockdown study in Romania to analyze and compare the evolution and type of injuries produced by electric scooters and motorcycle accidents, in the warm season.

Due to the atypical situation in the summer of 2020, the Emergency Department of the University Emergency Hospital Bucharest registered a decrease of the total number of presentations for minor and medium emergencies.

The Emergency Department of the University Emergency Hospital is located in the center of Bucharest, the capital of Romania. It is one of the largest emergency hospitals in Romania, graded as a regional hospital type $1 \mathrm{~A}$. In 2020 , the total number of presentations in the Emergency Department in the period 01.01-01.11 2020 was 72,860, the largest in Romania. In the study period of 01.06-30.09.2020, there were 28,779 presentations, out of which 437 were road accidents, marking a decrease by $33.78 \%$ 
compared to the same period of 2019 (660 road accidents). Out of these, $5.94 \%$ were electric scooter accidents, compared to $4 \cdot 39 \%$ in 2019. In the case of motorcycle accidents, there was a small decrease $(6.63 \%$ in 2020 , compared to $8.18 \%$ in the same 4 months period of 2019).

Comparing the study period with the same period of 2019, we noted a percentage increase in accidents by electric scooters, and a decrease in the case of motorcycle accidents.

The majority of people tried to be as prudent as possible, respecting the measures imposed by the authorities, avoiding closed and crowded places, and that implied an increase in the use of personal transport (cars, motorcycles, electric and manual scooters, electric and manual bicycles).

The increase in electric scooter accidents is probably due to the increase in number of electric scooters in Bucharest, caused by the proliferation of electric scooter rental companies [11], but also to a lack of protective equipment.

Global studies showed that protection equipment, especially the helmets worn by motorcycle drivers [12], minimizes damage $[13,14]$.

For electric scooter drivers, the helmet is mandatory only for ages between 14 and 16 years [9], and it is only occasionally worn by drivers aged older than 16 years. In a study conducted in the U.S. for a year [15], 94.3\% subjects did not wear any protection helmet.

The present study showed a predominance for the male sex and ages between 20 and 40 years, concordant with the data from other studies $[2,3,16,17]$.

It is a known fact that motorcycle accidents can result in severe, even deadly injuries [16, 18-20]. In our study, 1 motorcycle driver with severe polytrauma died in the Emergency Department, shortly after arrival.

Although the impact mechanisms are different, the study showed a small percentage difference between admitted patients, but also discharged patients, in both types of accidents, supporting the hypothesis on which this study was started, that electric scooter accident injuries are underestimated, and that these recreational devices can have a great damage potential, comparable to other vehicles with far higher speed.

The most frequent injury mechanism is by accidentally falling off the electric scooter, most injuries being musculoskeletal alone $(69.23 \%)$, or associated to other injuries (15.38\%). Furthermore, $34.8 \%$ of discharged patients needed immobilization, a higher percentage than those from motorcycle accidents. By comparing the percentage of musculoskeletal injuries in electric scooter accidents $(84.61 \%)$ to that of motorcycle accidents $(96.50 \%)$, the cost of imaging investigations, and the socio-economic implications of the partial functional impairment due to the immobilization of discharged patients, we could show the real "weight" of these small means of transport, so popular in crowded cities.

Our investigation had some limitations: firstly, due to the COVID-19 pandemic, the number of patients was smaller than normal. Secondly, it was a small study, following patients presented to only one emergency department, albeit a regional hospital, and the results could not be extended to the entire population. Thirdly, we could not collect the exact data referring to protective equipment, as it was not mentioned in all cases. Other studies showed that most motorcycle drivers wore a helmet [12], while most electric scooter drivers did not $[\mathbf{1 5}, \mathbf{2 1}]$.

Our suggestion for electric scooter drivers was to wear protective equipment, regardless of age and the lack of legal obligation.

\section{Conclusions}

We analyzed two different types of road accidents, produced by using a high-speed vehicle - the motorcycle - and a low-speed vehicle - the electric scooter. We found an increase in the number of presentations due to electric scooter accidents, compared to 
motorcycles, and, implicitly, of the injuries associated to them. The primary outcome was an increase in orthopedic injuries due to electric scooter accidents and the secondary outcome was an increase in severity and in the number of immobilizations by various orthopedic devices, in the case of discharged patients. We consider that current rules about protection equipment for electric scooter drivers must be re-evaluated, because their number is increasing and the impact of the injuries is underestimated.

\section{Conflicts of interest}

Authors state no conflict of interest.

\section{Informed Consent and Human and Animal Rights statements \\ An informed consent has been obtained from all individuals included in this study.}

\section{Authorization for the use of human subjects}

Ethical approval: The research related to human use complies with all the relevant national regulations, institutional policies, is in accordance with the tenets of the Helsinki Declaration, and has been approved by the review board of the University Emergency Hospital Bucharest, Romania.

\section{Acknowledgements}

We would like to thank the Statistics Department of the University Emergency Hospital Bucharest for providing essential documentation for this study.

\section{Sources of Funding}

None.

\section{Disclosures}

None.

\section{References}

1. BBC News 01.07.2020. Rental e-scooters will become legal on roads in Great Britain from July $4^{\text {th }} 2020$. https://www.bbc.com/news/uk-53219331.

2. Blomberg SNF, Rosenkrantz OCM, Lippert F et al. Injury from electric scooters in Copenhagen: a retrospective cohort study. BMJ Open. 2019; 9:e033988. doi: 10.1136/bmjopen-2019-033988.

3. Stoermann $P$, Klug $A$, Nau $C$, Verboket RD, Leiblein $M$, Mueller D, Schweigkofler U, Hoffmann R, Marzi I, Lustenberger T. Characteristics and Injury Patterns in Electric Scooter Related Accidents - A Prospective TwoCenter Report from Germany. J. Clin. Med. 2020; 9,1569.

4. Tan AL. Trauma Coordinators and Trauma Service Representatives, Chong CK et al. The price of personal mobility: burden of injury and mortality from personal mobility devices in Singapore - a nationwide cohort study. BMC Public Health. 2019; 19,880. https://doi.org/10.1186/s12889-019-7210-6.

5. Badeau A, Carman C, Newman MS, Steenblik J, Carlson M, Madsen T. Emergency department visits for electric scooter-related injuries after introduction of an urban rental program. AJEM. 2019. doi: https://doi.org/10.1016/j.ajem.2019.05.003.

6. Bloom MB, Noorzad A, Lin C, Little M, Lee EY, Margulies DR, Torbati SS. Standing electric scooter injuries: Impact on a community. American Journal of Surgery 2020. https://doi.org/10.1016/j.amjsurg.2020.07.020.

7. Reinberg S. ER visits for e-scooter injuries nearly double in one year. Medical Xpress. 31.08.2020.

8. OUG pentru reglementarea circulatiei trotinetelor electrice pe drumuri publice a fost adoptata in 04.02.2020/ pentru modificarea si completarea OUG nr. 195/ 2002. Gov.ro.

9. AutoBild.ro 07.02.2020. Trotineta electrica - definitie in legislatie. https://www.auto-bild.ro/stiri/legeatrotinetelor-2020-178158.html.

10. E-DRPCIV.ro. Motocicleta. https://www.edrpciv.ro/legislatie/codul-rutier-simplificat/.

11. ITNewz.ro 16.07.2020. Lista Cu servicii de inchiriere trotinete electrice din Bucuresti. https://www.itnewz.ro/servicii-inchiriere-trotineteelectrice-bucuresti/.

12. Insurance Information Institute, Motorcycle Helmet Use, 2000-2019.

13. Choi WS, Cho JS, Jang YS, Lim YS, Yang HJ, Woo JH. Can helmet decrease mortality of craniocerebral trauma patients in a motorcycle accident?: A propensity score matching. PLoS One. 2020; 15(1):e0227691. doi: 10.1371/journal.pone.0227691.

14. Chaichan $S$, Asawalertsaeng $T$, Veerapongtongchai $P$, Chattakul $P$, Khamsai S, Pongkulkiat $P$, Chotmongkol V, Limpawattana $P$, Chindaprasirt J, Senthong V, Ngamjarus C, Sittichanbuncha Y, Kitkhuandee A, Sawanyawisuth K. Are full-face helmets the most effective in preventing head and neck injury in motorcycle accidents?. A meta-analysis. Preventive Medicine Reports. 2020; Volume 19. https://doi.org/10.1016/j.pmedr.2020.101118. 
15. Trivedi TK, Liu C, Antonio ALM et al. Injuries Associated With Standing Electric Scooter Use, JAMA Netw Open. 2019; 2(1):e187381. doi: 10.1001/jamanetworkopen.2018.7381.

16. Granieri SS, Reitano EE, Bindi FF et al. Motorcyclerelated trauma: effects of age and site of injuries on mortality. A single-center, retrospective study. World J Emerg Surg. 2020; 15,18. https://doi.org/10.1186/s13017020-00297-1.

17. Hasan O, Sheikh S, Fatima A et al. Motor-vehicle Crash Patient Injury Patterns from a Level One Trauma Center in a Metropolitan City: A Cross-Sectional Study. Cureus. 2019; 11(2):e4073. doi:10.7759/cureus.4073.

18. Fletcher C, Mcdowell D, Thompson C et al. Predictors of hospitalization and surgical intervention among patients with motorcycle injuries. Trauma Surgery \& Acute Care Open. 2019; 4;eooo326. doi: 10.1136/tsaco-2019-000326.

19. Delamou A, Kourouma K, Camara BS, Kolie D, Grovogui FM, El Ayadi AM, Ade S, Harries AD. Motorcycle Accidents and Their Outcomes amongst Victims Admitted to Health Facilities in Guinea: A CrossSectional Study, Advances in Preventive Medicine. 2020; Article ID 1506148, 7 pages. https://doi.org/10.1155/2020/1506148.

20. Sayyed Hoseinian S, Ebrahimzadeh M, Peivandi $M$, Bagheri F, Hasani J, Golshan S, Birjandinejad A. Injury Patterns among Motorcyclist Trauma Patients: A Cross Sectional Study on 4200 Patients. The Archives of Bone and Joint Surgery. 2019; 7(4),367-372. doi: 10.22038/abjs.2019.35177.1926.

21. Kobayashi LM, Williams E, Brown CV et al. The emerging epidemic of e-scooters. Trauma Surgery \& Acute Care Open. 2019; 4:e000337. doi:10.1136/tsaco2019-000337. 